\title{
La gestación del proyecto: \\ Consorcio-concepción de Enrique Browne y Paneles Arauco de José Cruz Ovalle*
}

\author{
The origins of the project: \\ Consorcio-Concepción of Enrique Browne \\ and Paneles Arauco of José Cruz Ovalle
}

Rodrigo García Alvarado + Jorge Haris Jorquera +

Jessica Fuentealba Quilodrán + Rubén Muñoz Rodríguez

$<$ Resumen>

La formación en arquitectura requiere abordar esencialmente la enseñanza del proyecto. Con el fin de indagar su gestación en la arquitectura chilena contemporánea, se revisan dos obras recientes; Paneles Arauco y Consorcio de Concepción, que permiten vislumbrar posturas diferentes, pero una aproximación común

<Abstract>

Architectural teaching requires essentially to set design process. In order to study the outset of design in Chilean contemporary architecture this paper reviews the process of two recent buildings; Panels Arauco and Consorcio Concepcion, revealing different positions but one common approach.

-PALABRAS CLAVE>

DISEÑO ARQUitectónico / CREATIVIDAD / TEORÍA / ARQUITECTURA CHILENA / OFICINAS

<KEY WORDS >

ARCHITECTURAL DESIGN / CREATIVITY / THEORY / CHILEAN ARCHITECTURE / OFFICES
¿Cómo se origina el proyecto arquitectónico? ¿Qué determina esencialmente el diseño? ¿A qué obedecen sus formas y condiciones? Estas preguntas parecen tan sustanciales como difusas. Constituyen una capacidad central de la profesión de arquitecto y por ende, el aprendizaje principal de su formación. Pero parecen cubiertas por algún velo de misterio o aleatoriedad. Probablemente debido a la complejidad técnica, cultural y artística de la disciplina, como también a la diversidad creativa. Pero una actividad profesional que ha alcanzado un rol relevante en el desarrollo social, evidentemente posee un sustrato de principios compartidos. Sin embargo permanecen mayormente ocultos por una faceta discrecional. Lo que parece relevante esclarecer, especialmente en los ámbitos educacionales y sociales, porque estas condiciones se relacionan con los procesos, y también los valores del diseño.

\footnotetext{
* Depto. de Diseño y Teoría de la Arquitectura, Universidad del Bío-Bío, Concepción, Chile.
} 
En la Antigüedad (hasta bien entrado el Renacimiento), la gestación arquitectónica seguía preceptos reguladores, y de hecho había escasa conciencia del proyecto (aunque evidentemente diversas interpretaciones y evoluciones culturales). Es el Racionalismo (y la expansión de la sociedad) la que motiva una reflexión sobre la resolución del diseño total, despertando diversas condiciones y posibilidades. En el Modernismo, al cuestionar muchos presunciones vigentes, se enfatiza un planteamiento conceptual e individual de la obra, resurgiendo principios renacentistas de coherencia, autoría y creatividad. Las tendencias posteriores han remarcado la situación del lugar y contexto cultural del proyecto, y por ende involucrando mayores definiciones particulares. También es innegable que el conocimiento arquitectónico en la actualidad esta influenciado mayormente por revistas que exhiben obras individuales y exóticas, con un título conceptual que puede haber originado la creciente convicción que existe un sentido único y global que gobierna (y explica) la totalidad del diseño de un edificio. De este modo es usual hoy en día, especialmente en las escuelas de arquitectura, escuchar hablar de la «idea», «principio», «fundamento» 0 «concepto» del proyecto, algunos más pragmáticos mencionan el «partido general», los «antecedentes», «objetivos» 0 «decisiones» que definen e diseño; otros más difusos se refieren a la "cualidad», «valor poético», «metáfora» «aporte» de la obra. Este sentido gestor del proyecto es escasamente aclarado, y muchas veces voluntarioso, aceptado como una postura original al arbitrio del creador (y por tanto que no se puede cuestionar porque es una decisión personal y privativa, solo se puede revisar su aplicación), pero que implica una desatención u oscurecimiento de valores comunes. Incluso estas posturas están cada vez menos diferenciadas por estilos, tendencias, tipologías, situaciones geográficas o culturales, sino guiadas por preferencias individuales, muchas veces poco explicitadas, escasamente elaboradas o desarrolladas posteriormente al diseño. Aunque evidentemente esta definición configura significativamente (aunque no totalmente) la calidad del proyecto, su capacidad de resolver los requerimientos y congeniar de manera integrada los diferentes aspectos involucrados. Para los estudiantes resulta desconcertante que las obras profesionales, escasamente revelan algún principio global, sino más bien, parecen supeditarse a leyes de mercado o costumbres formales. Ocasionalmente algún arquitecto describe su obra y menciona conceptos, a veces sin explicar como se aplican en el proyecto, o sin criticar o asumir otras consideraciones posibles. Por lo que este requerimiento de fundamento general de la obra aparece como un extravagante recurso propio de la formación, como una manía de escuela, para impulsar la creatividad y coherencia (lo que no deja de ser cierto, pero debilita un análisis más profundo de principios generales de la disciplina). Estableciendo casi una dicotomía entre la formación y la profesión, más aún entre la arquitectura admirada en las escuelas (de revistas) y la arquitectura requerida socialmente, provocando un distanciamiento del público y de las necesidades culturales.

Este trabajo intenta dilucidar parte de este dilema, revisando la gestación proyectual de dos obras nacionales contemporáneas destacadas y realizadas por connotados arquitectos. Con el fin de esclarecer al menos un par de posturas cercanas y relevantes, que sirvan de alguna reflexión en el tema. Para esta revisión se analizaron las descripciones publicadas de cada proyecto, visitando las obras involucradas y otros proyectos de los mismos arquitectos, entrevistando a los autores y usuarios, revisando sus textos y contextos profesionales, además de múltiples discusiones internas.

\section{Consorcio-Concepción}

El edificio de la Compañía de Seguros Consorcio en Concepción fue proyectado por el arquitecto Enrique Browne (conocido por su relevante obra profesional y propuestas ecológicas). Se localiza en el centro de la ciudad, en una esquina algo rezagada hacia el rio Bío-Bío. Este edificio recibió el Premio Municipal de Arquitectura 2004 (año en que terminó su ejecución) y destaca por su altura entre las manzanas cercanas, con formas verticales suspendidas y un gran techo voladizo. A nivel peatonal configura la esquina con un ventanal curvo y luminosos recintos de ingreso. El planteamiento inicial de Browne (reiterado en distintas publicaciones), fue realizar un edificio «rectangular y económico», aparentemente en contraposición a otras alternativas triangulares y más sofisticadas que estudió durante el proyecto. También menciona su composición «neoplástica» y la conformación de un espacio urbano con la iglesia contigua, lo que explica en un esquema isométrico (de medidas algo desproporcionadas con la realidad), pero lamentablemente no se ejecutó esta plazuela. Los textos no comentan la distribución interior, y en la entrevista realizada sobre la obra adujo que las oficinas, que se advierten algo atestadas, fueron diseñadas por otros profesionales. Tampoco menciona mayormente las divisiones vidriadas y halles de acceso que reflejan un notable cuidado de terminaciones y desarrollo formal, apreciado por los visitantes y usuarios.

Browne ha planteado extensamente una atención con la geografía, la vegetación, la luz y los trazados. Utilizando especialmente los parrones, inspirados en la arquitectura tradicional chilena, como elementos configuradores en casas contemporáneas y en la fachada de edificios de altura, como el Consorcio de Santiago proyectado en 1982 (con Borja-Huidobro). En el edificio de Concepción volvió a utilizar esta estrategia en las fachadas soleadas, aunque con entramados de madera y otras especies que no han tenido mucho crecimiento. Estos elementos protectores de los volúmenes de los recintos, son particularmente explicados de manera gráfica en los artículos que exponen la obra. También explica la elección de madera y revestimientos metálicos para el edificio de Concepción, como materiales del lugar y nombra un par de empresas de la zona. En la entrevista le comentamos que la ciudad se caracteriza mayormente por un hormigón algo mohoso, y que la madera y el metal son trabajados de una manera distinta a como están utilizados en el edificio. Sin embargo indudablemente la utilización de esos materiales constituyen un aporte novedoso a la ciudad y se combinan con otros detalles notables en las escaleras, entradas de luz, soluciones estructurales, etc., que revelan su experiencia y capacidad profesional en obras de magnitud y complejidad.

\section{Paneles $A$ rauco}

Las oficinas de Paneles Arauco están localizadas más de 100 km. al sur de Concepción, al interior del camino principal, y fueron proyectadas en 1997 por José Cruz Ovalle. Este arquitecto ha sido conocido por diseñar el Pabellón de Chile en la Feria de Sevilla de 1992 y recientemente la sede Peñalolen de la Universidad Adolfo Ibáñez que obtuvo el Premio Iberoamericano de Arquitectura 2004. Las oficinas de Paneles Arauco es una pequeña construcción gris de un piso con extrañas ventanas y salientes de la techumbre, adosada a los grandes galpones industriales. La explicación oficial de la obra (repetida también de manera similar en los tres libros que han publicado), comienza argumentando la mayor libertad de diseño que permiten las oficinas frente a las imposiciones de ingeniería que exige la planta industrial. Planteando equiparar la gran diferencia de dimensiones entre la fábrica y los recintos de trabajo, a través de convertir un recorrido de extensión lineal a circular. En la entrevista 
personal recordó además la inmensidad del paisaje y el clima cambiante, para justificar un edificio ensimismado interiormente. Contraponiendo esta condición del lugar, con su vivencia personal de mediterráneo y secano, con cielos permanentes y áridos paisajes.

El interior de Paneles Arauco destaca principalmente por sus singulares muros curvos y continuidades materiales, que

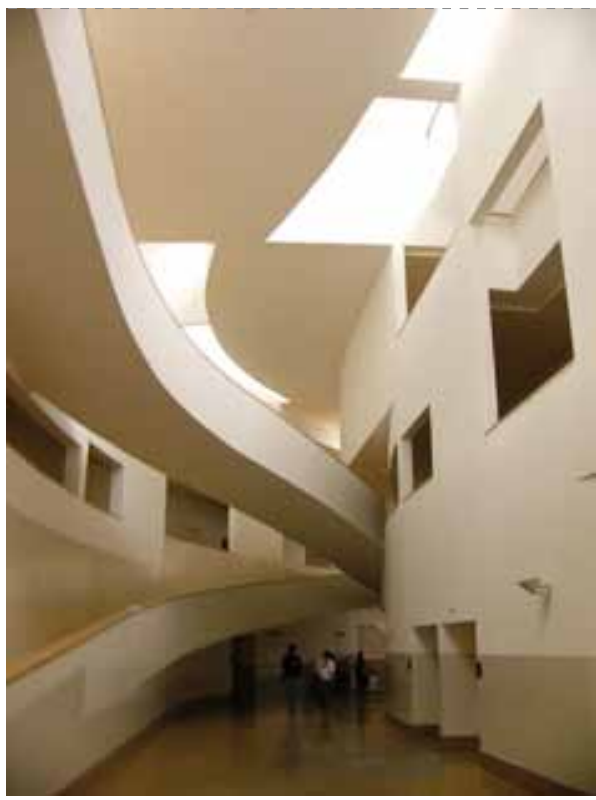

Interior de la Universidad Adolfo Ibáñez en Peñalolén (Fotografía: Ruben Muñoz) indudablemente refiere a los productos realizados por la empresa. A pesar que en los planteamientos de la obra Cruz reniega de la expresión comercial del edificio (con lo que fundamenta el color gris de las fachadas), los tabiques interiores indudablemente se convierten en promotores de los elementos fabricados por la empresa. Sostiene persistentemente la idea de "abstraerse» de la representación comercial, de la

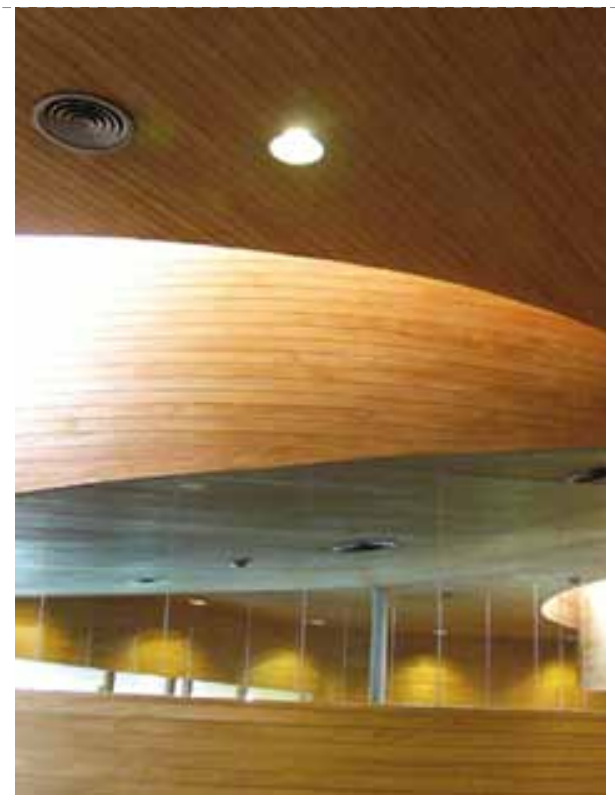

Interior Paneles Arauco

(Fotografía: Rubén Muñoz). magnitud industrial y el entorno local, aunque precisamente algunos de estos aspectos fundamentan su diseño. La «abstracción» parece tener un sentido más propio y profundo en el pensamiento de Cruz, que intenta explicar largamente en la entrevista y lo sugiere para titular su antología. También remarca en sus publicaciones, la condición única de cada obra, ajena a la repetición, a pesar de las evidentes similitudes.

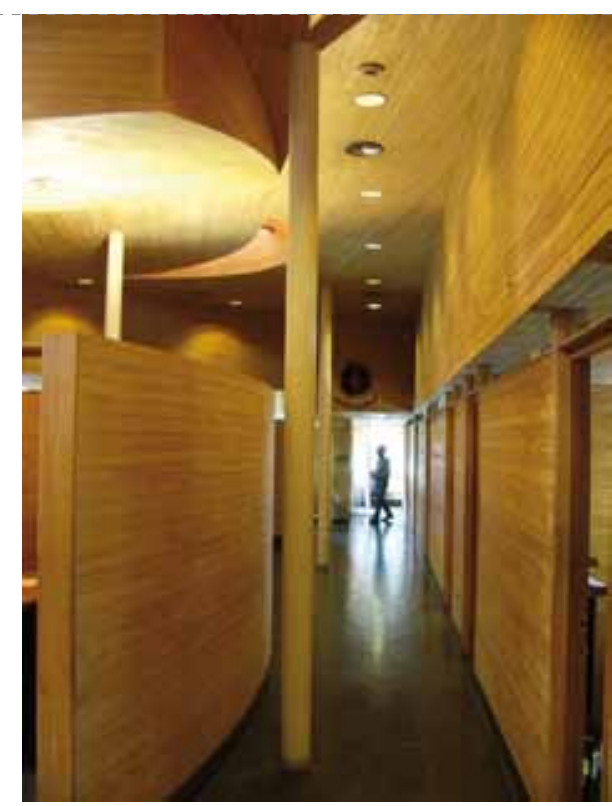

Interior Paneles Arauco

(Fotografía: Rubén Muñoz)

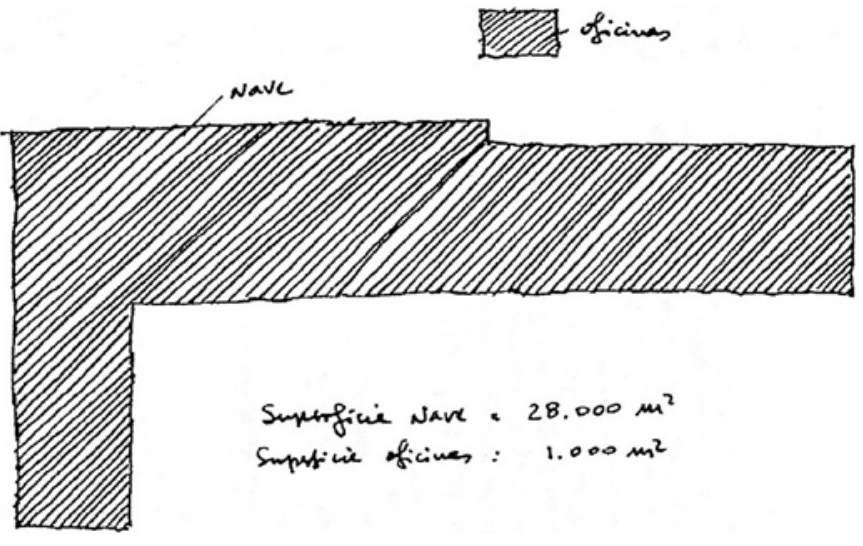

Esquemas Paneles Arauco (José Cruz Ovalle).
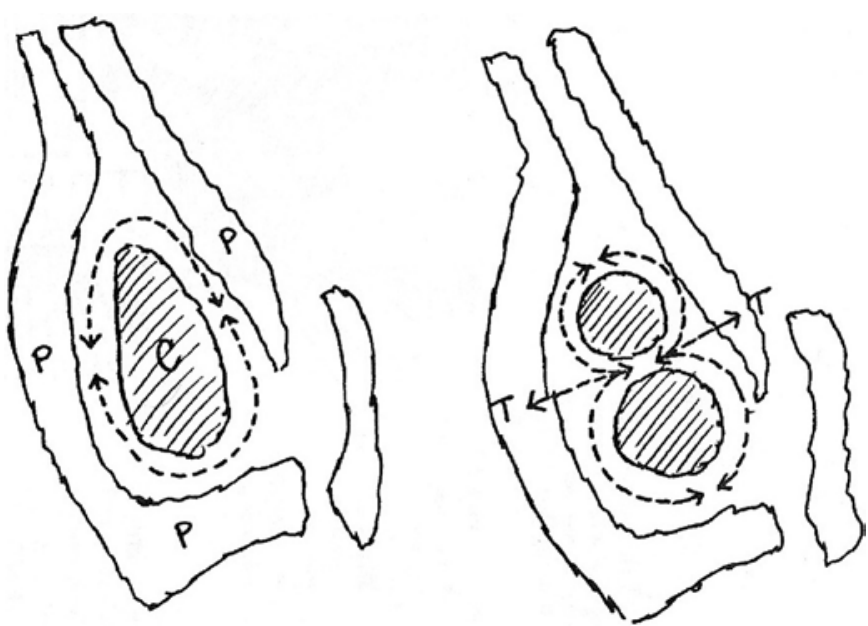

Esquemas Paneles Arauco (José Cruz Ovalle). 


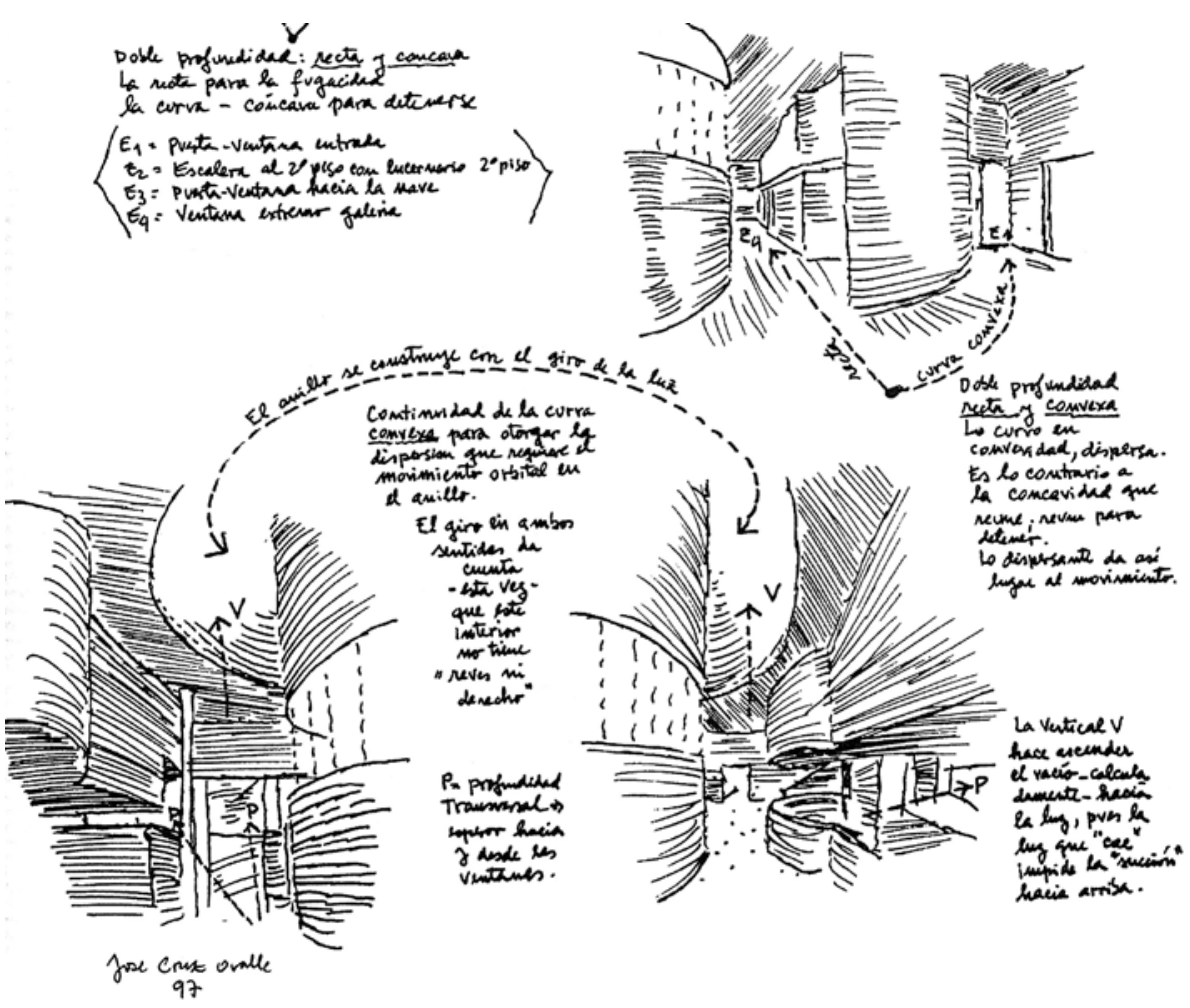

Esquemas Paneles Arauco (José Cruz Ovalle).

Las publicaciones que exhiben las oficinas de Paneles Arauco presentan croquis de José Cruz que explican la distribución interior y vistas de los pasillos. Planteando gráficamente que las salas de reuniones se agrupan al centro para crear un anillo de circulaciones que extienda las distancias recorribles, otorgando una «autonomía del interior». Plantea la necesidad de crear una presencia a partir del «espesor de su vacío interno construido por la proximidad que otorga el tacto». Lo que fortalece con las oficinas en el borde y los ingresos desfasados de las circulaciones. Estableciendo de este modo un deambular que según sus palabras, «multiplique el espacio y cree la infinitud». Diversos dibujos detallan los ingresos de luz por la techumbre y las formas cóncavas y convexas de los muros, con notas sobre sus cualidades sensibles.

Prácticamente no menciona las características constructivas de sus obras. Pasando por alto, por ejemplo, la hábil resolución estructural que logra la libertad interior y lucarnas por una techumbre metálica escondida y soportada en pilares independientes de los cerramientos. Como también la evidente condición de la madera, aunque menciona la situación luminosa, que logra en virtud de las superficies explicándolo como «lo suavemente sombreado mas nunca lo sombrío». Cruz insiste mucho en su trabajo escultórico paralelo, donde se permite "consumar el espacio», estudiando la forma y su soporte a través de la experimentación directa con lo materiales. Aunque reconoce su diferencia con la arquitectura, que debe servir la vida y sujetarse a diversas restricciones, en este sentido plantea una actitud receptiva frente a las condiciones de cada encargo, indicando que «no hay circunstancia desfavorable» y todas pueden recogerse en el proyecto.

\section{Gestación}

En ambos proyectos, aunque constituyen aproximaciones diferentes, se pueden advertir ciertas similitudes en el proceso de gestación (de acuerdo a lo que expresan las publicaciones y entrevistas), y naturalmente divergencias en su aproximación, decisiones y resultados. En una primera instancia Cruz menciona para los Paneles Arauco la diferencia de magnitud entre el edificio solicitado y la planta industrial, es decir establece al comienzo del proyecto un problema de volumen. De manera similar Browne presenta la obra indicando que es la alternativa más simple y económica, aparentemente recordando otras posibilidades formales, lo que también hace referencia a cierto volumen determinado previamente (una «torre vertical», a partir de la cantidad de oficinas requeridas en el sitio indicado). En ese sentido reconocer la «masa» del encargo, su dimensión general como espacio ocupado, parece ser el primer momento del diseño, insinuando algunas connotaciones funcionales, estructurales y de localización. Más aún, en el caso de Cruz, plantea inmediatamente una relación de longitud recorrida, es decir de aspectos vivenciales, proponiendo operaciones geométricas al respecto (es decir volviendo al estudio formal). Mientras Browne comenta la conformación de la plazuela con la iglesia. En este sentido, se reconoce cuan imbricados están las distintas consideraciones de proyecto, pero asimismo se advierte un segundo momento del proceso de diseño, en que se analizan las posibilidades espaciales del volumen inicial. En un caso (Cruz), en los interiores y en otro (Browne) en los exteriores. Esta distinción pareciera provenir de la diferente localización de ambas obras (en la ciudad y el campo, respectivamente), pero en alguna medida también suponen, que los otros aspectos espaciales (el exterior de Paneles, sin relevancia local, y el interior de Consorcio, como plantas libres de oficinas), no merecen mayor cuestionamiento, reconociendo de esta manera también una focalización en ciertos aspectos espaciales específicos. La obra de Cruz parece surgir desde "adentro», desde la vivencia cotidiana del usuario, mientras la obra de Browne parece originada desde "afuera», desde la imagen social y cultural del edificio.

En un tercer momento, parece haber una elaboración más detallada de la solución de diseño. En el caso de Paneles, se realiza una elucubración respecto a alternativas de formas para los recorridos en relación a los recintos necesarios, y en el caso del Consorcio, de las volúmenes compositivos. Es decir, se toma conciencia del programa y de la articulación formal, de la escala en términos globales. Asumiendo también ciertas posibilidades funcionales o constructivas (con una cultura previa de ocupación espacial y de soluciones arquitectónicas)

Luego parece surgir un cuarto momento inmediatamente emergente en torno a la configuración espacial de los recintos, en un caso por los muros curvos y cielos desfasados, y en otro por las caras y cubiertas de los volúmenes. Lo que se vincula a la actividad y a ciertas alternativas de ejecución. 
En un quinto momento parece haber una elaboración particular del detalle material o formal, al menos en un sentido espacial. Por ejemplo en Paneles, con los «espesores de luz» de la techumbre, que indudablemente se relaciona con una definición constructiva y da por resuelto la distribución arquitectónica. A su vez en Consorcio se plantean los revestimientos y en particular el entramado que regula la imagen y comportamiento térmico.

Curiosamente en ambos no hay menciones de los sistemas estructurales y modulaciones utilizadas, aunque poseen opciones singulares (una estructura metálica sobrepuesta e independiente en los Paneles, marcos de hormigón que soportan los distintos volúmenes y techumbre colgante en Consorcio). Sin embargo da la impresión que estos aspectos sustanciales ya han sido estudiados en esta etapa del diseño, y omitidos en el discurso arquitectónico simplemente por el oficio de los profesionales y la proyección de las decisiones más visibles.

En todo caso, hay planteamientos expresos sobre condiciones materiales, aunque fundamentalmente superficiales, lo que parece constituir un sexto momento. En Paneles mencionando los revestimientos de madera, la veta y su efecto luminoso ( «suavemente sombreado») y en Consorcio, la utilización de la madera y planchas metálicas como vinculadas a la zona.

Las explicaciones suelen culminar con aspectos espaciales secundarios, como la profundidad en Paneles y la vista superior al río en el Consorcio, es decir como logros o resultantes beneficiosas, pero no estructurantes, como un séptimo momento.

No hay mayores comentarios sobre la definición de recintos y circulaciones o accesos que indudablemente son relevantes e implican probablemente el estudio de diversas alternativas de distribución. Así como también de localización de servicios que pueden incidir aunque probablemente en menor medida.

\section{Conclusión}

En ambos procesos de gestación se reconoce una cierta secuencia, avanzando en detalle desde un origen similar, pero también abordando integralmente los aspectos del diseño arquitectónico. Este camino parece bastante común, pero también dependiente del encargo específico. Indudablemente van asumiendo predilecciones reiteradas de cada arquitecto, como su «estilo», más que en el desarrollo, en las preocupaciones planteadas y progresivamente retomadas y refinadas.

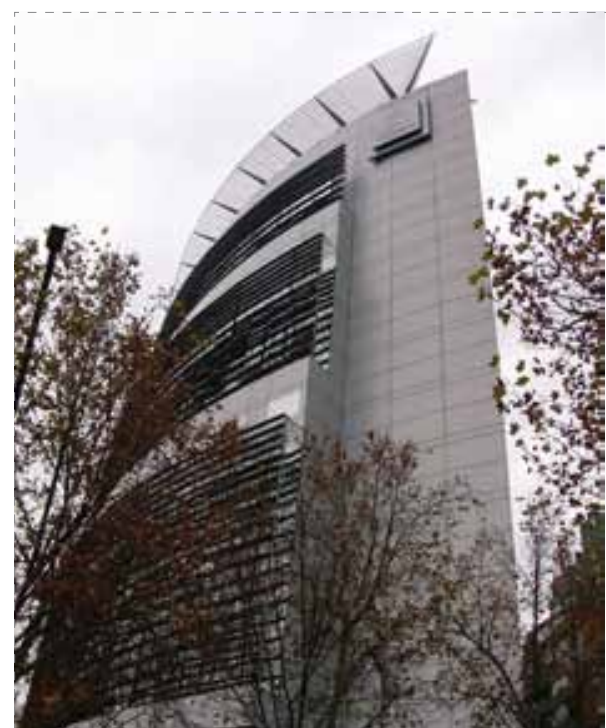

Edificio Consorcio Santiago

(Fotografía: Rubén Muñoz).

Esta personalidad individual indudablemente contribuye a la elaboración y conocimiento acumulado, así como a la identidad de la obra, pero habitualmente oscurece los sentidos generales por exacerbar procedimientos o posturas particulares. Un aspecto relevante es reconocer como la solución formal actúa como integrador del problema de diseño, pero éste es permanentemente determinado por su ocupación, comportamiento o relación humana, que parece ser un eje fundamental de la formulación arquitectónica (como una reacción vivencial a la forma)

En estas obras la gestación del proyecto no es un concepto abstracto, ni una metáfora sofisticada, ni una cualidad huidiza o una situación congelada, una traslación de las ciencias o la literatura, una influencia geográfica o histórica, una manera personal o problema individual, una sensibilidad pura o una mecánica determinada, una inspiración mitológica o una receta repetida. Sino, de acuerdo a estas dos experiencias analizadas, el fundamento $u$ origen del proyecto parece no ser un concepto único, sino un proceso, una elaboración proyectual con decisiones formales que implican modalidades de ocupación, análisis de posibilidades, de acuerdo a situaciones existentes o referencias previas, vinculadas a condiciones arquitectónicas, en un planteamiento encadenado con el desarrollo del proyecto. Más cerca de procesos regulares cargados de experiencia, capacidad y visión particular, pero lejos de una oscura aleatoriedad individual.

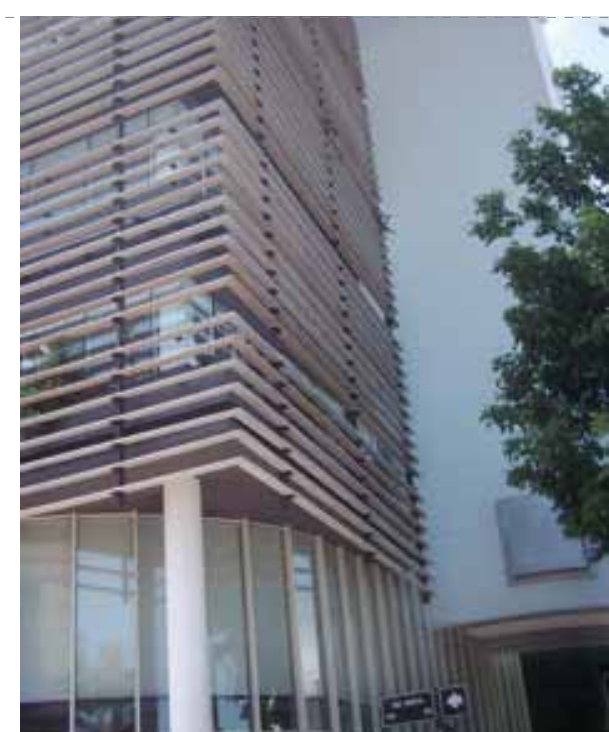

Entrada Consorcio Concepción (Fotografía: Jessica Fuentealba).

\section{Agradecimientos}

Este trabajo forma parte de la investigación DIUBB 720.1. La Teoría de la Obra, y ha sido realizada con el apoyo del Departamento de Diseño y Teoría de la Arquitectura de la Universidad del Bío-Bío. Se agradece también la valiosa colaboración de los arquitectos Enrique Browne y José Cruz Ovalle.

\section{Bibliografía}

AA.VV. «Edificio CNS Concepción», Revista CA. Benett, E.; Crispiani, A. José Cruz Ovalle. Hacia una nueva abstracción. Santiago de Chile: Ediciones ARQ, 2004

Browne, E. «Casas y Escritos». Taller América, Santiago, 1989

Browne, E. Otra Arquitectura en América Latina. México: Editorial Gustavo Gili, 1988.

Crispiani, A. Aproximaciones: De la arquitectura al detalle. José Cruz. Fragmento, simultaneidad y totalidad. Santiago de Chile: Ediciones ARQ, 2001

CS. «Green Screen». Architectural Review 2005; 77-79.

Lamas, J. «Edificio Consorcio en Concepción: Identidad Urbana». Revista BIT 2005; 42:7075

Liernur, F. Industrias. Obras de arquitectos chilenos contemporáneos. Santiago de Chile: Ediciones ARQ, 1998 

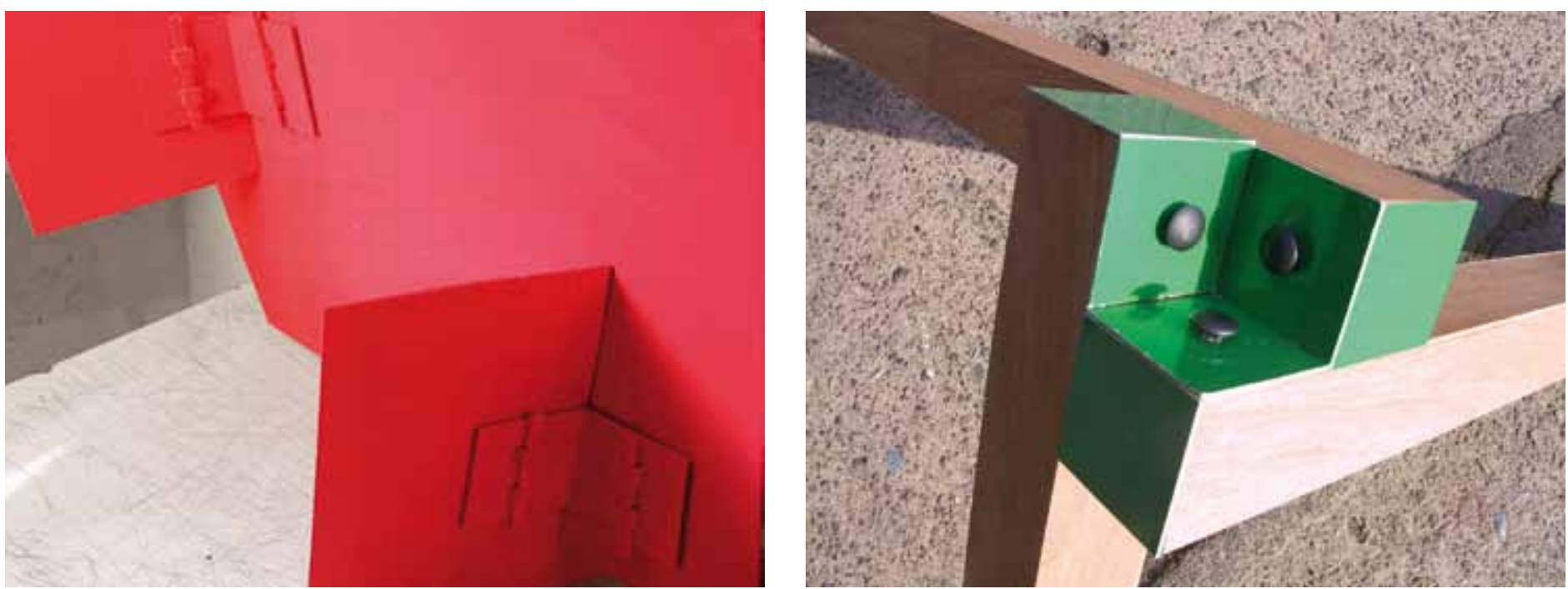

FE DE ERRATAS

En la Revista De Arquitectura $N^{\circ} 14$, en el artículo "Formación estética cuando la belleza ya no es una categoría», de los autores Sofía Letelier P. + Cecilia Wolff $C$

\section{- Página 80}

dice: ... aunque con retrazo

debe decir: ... aunque con retraso, ...
- Página 82

dice: ... imperfección la naturaleza ...

debe decir: ... imperfección de la naturaleza ...

- Página 82

dice: Después de racionalismo

debe decir: Después del racionalismo ....

- Página 82

dice: ... se valora subjetividad y memoria debe decir: ... se valora subjetividad y la memoria
- Página 82

El párrafo «Estos dos ejemplos se enunciaron (...) que era imposible prever». Al final de la página se debe omitir.

- Página 86

dice: ... entre los que cave ...

debe decir ... entre los que cabe ...

Autoría fotografías: $3^{\circ}$, Tang; $9^{\circ}$, Vilches.
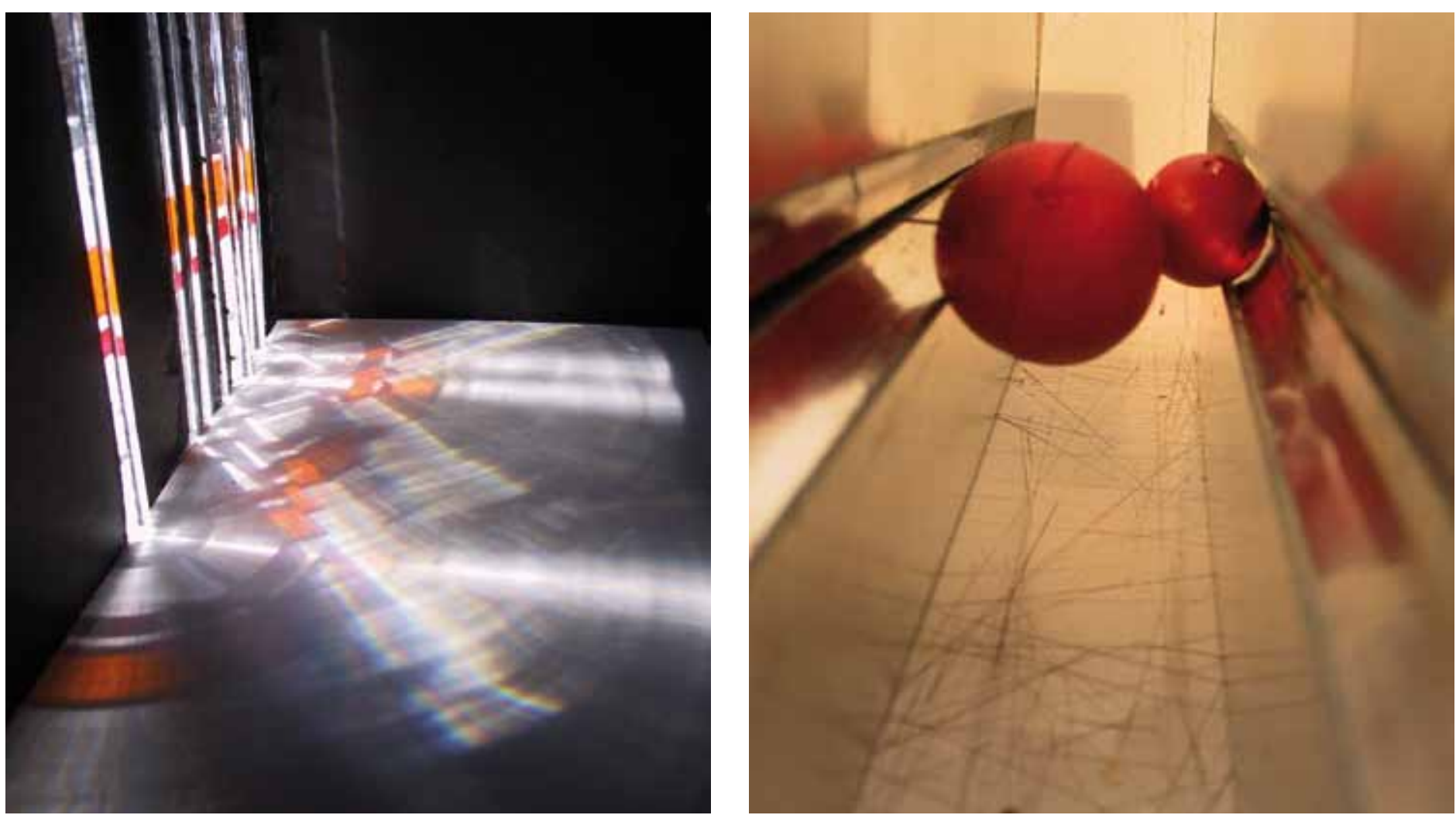